\title{
Papillary fibroelastomas: our case series and brief literature review
}

\author{
Alen Ružićc ${ }^{*}$, Tea Zaninović Jurjević, Željko Plazonić, Željka Diklić, Luka Zaputović, Ante Matana \\ University Hospital Center Rijeka, Rijeka, Croatia
}

Papillary fibroelastomas (PFEs) are rare, benign and generally slow growing tumors of the heart. According to the incidence, they are the third cardiac tumors (after myxoma and lipoma) and represent about $10 \%$ of primary intracardiac tumors. Although histologically benign, they cannot be considered as harmless endothelial lesions and may serve as a nidus allowing formation of large superimposed thrombi over a short period of time. Related embolic events are frequent involving adults in their active period of life. PFE-s are usually small (mostly 9-12 $\mathrm{mm}$ in diameter) and their recently described more frequent finding is associated with the advancement of diagnostic methods. They can be sessile or pedunculare, with stems 1-3 mm long, mostly solitary, and multiple in less than $10 \%$ of cases. PFE occur most commonly on the valves, respectively on the left side of the heart and they are the most common valvular heart tumors. The aortic valve is the primary involved location followed by the anterior mitral leaflet, while PFE can be found rarely on other valves, chordae, and papillary muscles. Approximately $1 / 2$ of patients have symptoms related to PFE (amaurosis fugax, transient ischemic attack, stroke, angina, myocardial infarction, ventricular tachycardia / fibrillation, syncope, sudden death, acute valvular dysfunction). The symptoms are the result of a mechanical effect of the tumor or occur due to the embolisation. Transesophageal echocardiography is the recommended method for diagnosis, with an overall sensi- tivity of $77 \%$. Symptomatic PFE-s should be surgically resected while the treatment of asymptomatic tumors is less clear. Large, left-sided, pedunculare and mobile tumors that grow fast should be excised to prevent sudden death and embolisation. Small (less then $10 \mathrm{~mm}$ in diameter) and nonmobile tumors that do not have the contact with the coronary ostia may be clinically followed-up with serial echocardiography examinations and removed if they increase in size, become mobile or symptomatic. This benign valve tumors usually do not recur. In this study we present our clinical experience with PFE-s and the review of the literature. On our clinical series, we will show interesting morphological variations and unexpected clinical presentation of these (maybe) not so rare and (definitely) not insignificant cardiac tumors.

KEYWORDS: heart valves, benign heart tumors.

Received: $20^{\text {th }}$ Mar 2013
*Address for correspondence: Klinički bolnički centar Rijeka, Tome Stržića 3,
HR-51000 Rijeka, Croatia.
Phone: +385-51-407-149
Fax: +385-51-218-059
E-mail: alen.ruzic1@ ri.t-com.hr

\section{Literature}

1. Burke AP, Tazelaar H, Gomez-Roman JJ, Loire R, Chopra P, Tomsova M, et al. Benign tumors of pluripotent mesenchyme. In: Travis WT, Brambilla E, Muller-Hermelink HK, Harris CC, editors. Pathology and genetics of tumours of the lung, pleura and heart. World Health Organisation Classification of tumours. Lyon: IARC; 2004. p. 260-5.

2. Butany J, Nair V, Naseemuddin A, Nair GM, Catton C, Yau T. Cardiac tumours: Diagnosis and management. Lancet Oncol. 2005;6:219-28.

3. Boodhwani M, Veinot JP, Hendry PJ. Surgical approach to cardiac papillary fibroelastomas. Can J Cardiol. 2007;23:301-2.

4. Grebenc ML, Rosado de Christenson ML, Burke AP, Green CE, Galvin J Primary cardiac and pericardial neoplasms: radiologic-pathologic correlation. Radiographics. 2000;20:1073-103. 